\title{
NUMERICAL MODELLING OF SOIL-NAIL AND SECANT PILE IN PLAXIS 2D: A CASE STUDY OF TOMB OF JAM NIZAM-AL-DIN SAMOO, MAKKLI THATTA
}

\author{
Syed Raghib Abbas SHAH ${ }^{1}$, Aneel KUMAR ${ }^{1}$, Tauha Hussain ALI ${ }^{1}$, Muhammad \\ Rehan HAKRO ${ }^{1, *}$, Mohammad Achar ZARDARI ${ }^{1}$ \\ ${ }^{1}$ Mehran University of Engineering \& Technology, Jamshoro, Pakistan. \\ corresponding author: rehan.hakro@faculty.muet.edu.pk
}

\begin{abstract}
The majority of historical heritage structures of Makli, Thatta require rehabilitation. As the Tomb of Jam Nizam-al-Din Samoo is near the slope's edge, the settlement increased due to slope degradation. This study aims to investigate the effect of structural elements such as secant pile and structural nails on the settlement of Tomb. From this study, it was observed that with the installation of secant piles on the slope, Tomb's settlement can be reduced considerably; moreover, the anchors did not have an appreciable role in the settlement. The secant pile of $12 \mathrm{~m}$ sufficient to reduce settlement. This will be economical and easy approach as compare to the retaining wall. The Factor of safety (FOS) reduced from 1.36 to 1.10 with increase of slope from 45 to 35 . The FOS of slope also increased with the installation of nails from east side of slope. The will reduce the chances of slope failure and consequently the tilting/collapse of Tomb.
\end{abstract}

\section{Keywords:}

Numerical modelling;

Plaxis 2D;

Secant pile;

Factor of safety;

Rehabilitation of old structure.

\section{Introduction}

The geological climate has an integral effect on historical monuments. Several complex geological processes (weathering/erosion, surface movements, and earthquakes) significantly affect the stability of such structures throughout their lifetime [1].

The movement of the earth's soil, its differential settlement, its rotation, or any other consequence of the structure's contact with the soil also causes structural damage to the architectural heritage. Although it is essential to examine every structure for shear resistance as well as underlying settlements [2-4].

Makli, also known as Makli Hill, is a hill situated 3.2 kilometers from Thatta on the road connecting Thatta and Karachi. Makli is one of the world's largest burial grounds, containing funereal tombs of rulers, warriors, saints, and their clans. It was first known as a funeral site in the 14th century, after the ruling monarchs used it as a burial ground for four centuries. According to UNESCO [4], this is currently designated as a safe world heritage site by UNESCO [4]. 


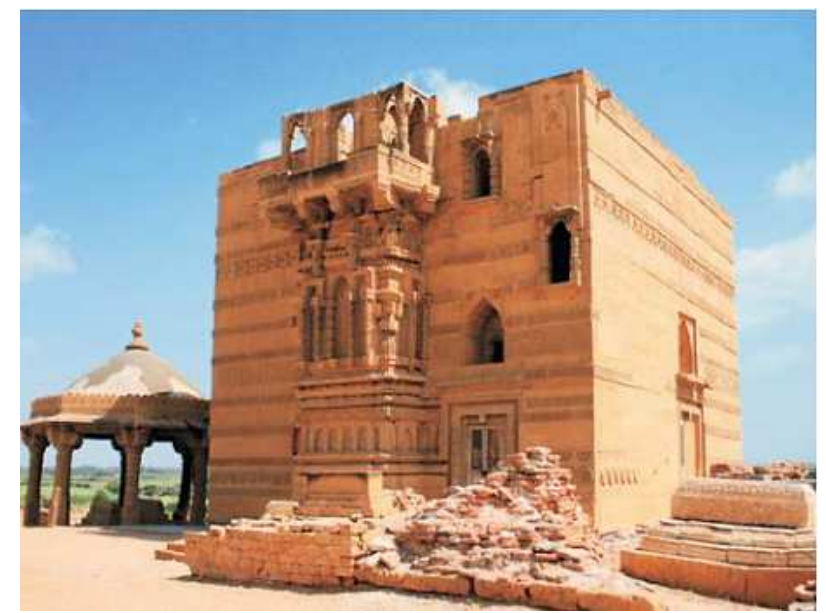

Fig. 1: Tomb of Jam Nizam-al-Din Samoo.

The Tomb of Jam Nizam-al-Din Samoo (Jam Nindo), Makli, Thatta, is a massive stone building dating from the 15th century, Fig. 1. By documenting the deformation in the surrounding land and human vandalism, disturbing growth in the building formed diagonal cracks. The monument has seen 8 inches of differential settlement, which is striking. There is also a prominent crack on the East side that runs parallel to the East wall. It's unclear if the break in the floor caused by soil erosion or is a joint between the suspected retaining wall, which constructed in 1994 [5]. From preventing the monument from collapse, immediate action needs to be sought to halt the deterioration. Already, in the inclinometer installed at different locations in historical buildings, measurements indicated settlement and creep behaviour in the Tomb structures, more specifically the tombs located near the slope. For the safety and stability of this various steps were taken such as improving the drainage conditions etc. Some efforts were made to stabilize the slope in the past by constructing retaining wall; however, it was not the technical solution of the problem. Analytical investigations are critical pre-conservation measures that will aid in monument conservation [6].

Secant pile walls are usually installed as retaining structures and support systems for deep foundations, retaining elements and at the same time load-bearing walls and deep foundations. For more than five decades piles, structures made of piles (pile wall, pile box, etc.) and pile-like structures (sockets, shafts, slurry trench walls, etc.) have been applied for retaining structures in (creeping) slopes.

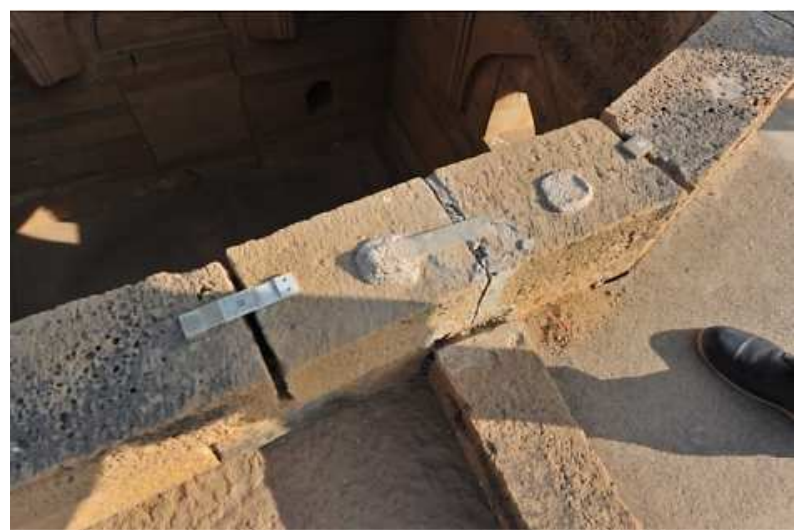

Fig. 2: Monitoring of movement at the Tomb site.

In situ retaining walls such as secant and contiguous pile walls and diaphragm walls, are widely used to minimize lateral and vertical ground movements, Fig. 2. This paper presents the results of efforts to evaluate the installation of a secant pile on the safety and stability of an ancient tomb located near the slope. Many analytical methods for the response analysis of piles under combined loads have been established in recent years. A simple method for designing a pile base under combined loading was proposed by Comodromos et al. [14]. By varying the slope angle and relative density of the soil, Begum and Muthukkumaran [15] were able to investigate laterally-loaded piles on a sloped surface. Full-scale shaft load tests with axial or lateral load only were recorded by Chien et al. [16]. According 
to the test results, 63 percent of the pile head displacement resulted in a combined load equal to the lateral load when tested under the same lateral load.

Meyerhof [7] developed an empirical formula to estimate a footing's bearing capacity on a slope face and crest for both fully cohesive and cohesionless soils.

Xie et al. [17] conducted experiments on a single pile at various locations on the slope with horizontal loading and unloading, concluding that pile pressure decreased as the distance from the slope increased.

The load-bearing pressure of a footing on a cohesionless soil slope was investigated by Graham et al. [8]. They compared their findings to Shields et al. [9] experimental data and discovered a successful match. To determine the bearing capacity of a base near a slope, Saran et al. [10] used the limit equilibrium and limit analysis methods. The two methods were shown to yield nearly identical results in the form of non-dimensional bearing ability variables, which are influenced by soil friction angle, slope inclination, and footing edge distance.

Zhang et al. [18] used the combined effect of the slope's vertical and horizontal loads to simulate pile load and deformation. Under combined force, the vertical load could effectively reduce the pile's bending moment and lateral displacement, according to the report [11].

Although the field test is the most effective method for investigating pile response for varying slope angles and edge distances, it is not always cost-effective, particularly when collecting experimental data for a variety of field cases [12]. The use of mathematical modelling to analyse the response of laterally loaded piles in sloping ground can be a cost-effective method. The finite element (FE) modelling method offers a more detailed tool that can incorporate different aspects such as soil continuity and pile-soil interface behaviour $[13,14]$. This study aimed to analyze a secant pile and anchor installation using Plaxis 2D software to determine the impact on the settlement of the Tomb and FOS of slope. The simulation analysis also examines the effects of slope and loading on the settlement of laterally loaded single piles on slope sites, with the goal of further elucidating and summarizing the bearing characteristics of laterally loaded secant piles on slope sites and providing guidance for practical engineering design and optimization.

\section{Geotechnical investigation}

The sub-soil investigation has been conducted by drilling 4 boreholes surrounding the Tomb in this study, Fig. 3. The field and laboratory testing performed for determination of geotechnical properties of sub-soil, such as moisture content, sieve analysis, Atterberg's limits, unconfined compression strength and standard penetration test (SPT). A weathered limestone layer followed by the cohesive and cohesionless soil encountered at the site. The maximum liquid limit and plasticity index were $66 \%$ and $17 \%$, and unconfined compression strength of was $0.2482 \mathrm{MPa}$ of sandy clay, 1.647 MPa of shale and 27.96 MPa of limestone. The tomb is founded on rock formation, though it is highly weathered near the surface zone. It is competent to support the load of present structure. The tomb is located just at the edge of rock slope (Eastern Side). The inspection shows a very clear sign of continued weather.
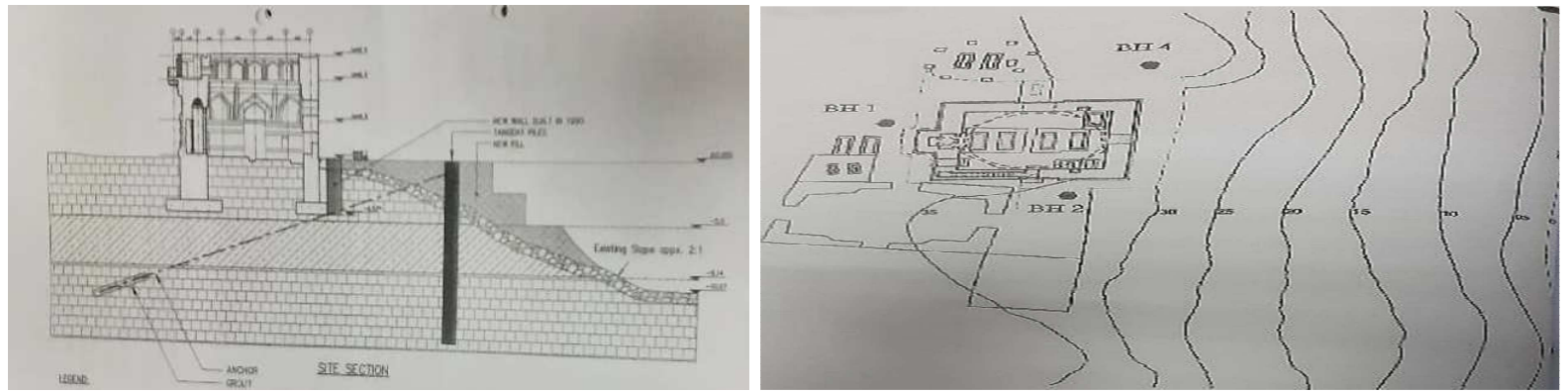

Fig. 3: Borehole locations and structural support.

Shale (Psudo-Rock) sandwiched between limestone layer top and bottom. The physical characters determined from laboratory test the exposed layer of soil lack cementation and cohesion, such as soil prone to degradation when exposed to atmosphere. The first layer sand/clay with gravels/cobbles, 2nd layer as highly fractured nodular limestone, 3rd layer consist of slity shale and forth layer as limestone and sandstone with seams of shale. 


\subsection{Description of soil investigation}

1st layer consists of sand/clay with gravels/cobbles (limestone) encountered from existing ground level and extended up to 1 meter.

2nd layer consist of slity shale.

3rd layer consist of highly fractured jointed nodular limestone and calcareous sandstone interlayer with seams of shale.

\section{Numerical modelling}

In this analysis, the FE code PLAXIS 2016 used. PLAXIS, which created specifically for geotechnical applications, includes a variety of basic and advanced soil models. PLAXIS allows various constitutive models to represent the behaviour of geomaterials. The prime difference between those models is the efficacy with which the stress-strain behaviour of the soil can be properly defined [15]. Using 15-node triangular components and plane-strain model of half of the system developed. According to the PLAXIS, the concrete secant pile wall represented by plate components. The subsurface stratigraphy modelled as a similar to field conditions in Plaxis. The Mohr-Coulomb (MC) model chosen for soil, and linear elastic model used to model the reinforced concrete secant pile wall. The secant pile modelled as plate element in Plaxis The input parameters for model is given in the Table 1. A ground anchor can be modelled as a node-to-node anchor combined with an embedded beam. The embedded pile is a representation of the grouted portion of the anchor, whereas the nodeto-node anchor is a representation of the free length [16]. The properties of ground anchor are mentioned in Table 2.

\subsection{Mohar-Coloumb model}

The Mohar-Coloumb model is user-friendly model and has practical approach and it requires a minimal number of features that soil shows in reality. The first-order approximation of soil behaviour represented through Mohar Coloumb model [17]. The use of Mohar-Coloumb Model is advisable according to Brinkgreve (2006) to get assessment of deformation in the soil due to loads. As other models require a large number of parameters as input as compare to Mohar-Coloumb. The MohrCoulomb model is an elastic-perfectly plastic model that is frequently used to represent soil behaviour in general and acts as a first-order model. In general, the model's stress-strain relationship behaves linearly in the elastic range when two defining factors from Hooke's law are used (Young's modulus $E$, and Poisson's ratio $v$ ). There are two parameters that determine the failure criterion (friction angle $\phi$, and cohesiveness $c$ ), as well as a parameter that describes the flow rule (dilatancy angle, which is derived from the use of a non-associated flow rule to simulate a genuine irreversible volume change due to shearing).

Table 1: Input model parameters

\begin{tabular}{|l|c|c|c|c|}
\hline \multicolumn{1}{|c|}{ Parameters } & Top soil & Shale & Limestone & Pile \\
\hline Unit weight $\gamma\left[\mathrm{kN} / \mathrm{m}^{3}\right]$ & 15 & 17 & 18 & 24 \\
\hline Modulus of elasticity $E\left[\mathrm{kN} / \mathrm{m}^{2}\right]$ & 15000 & 18000 & 50,000 & ---- \\
\hline Cohesion $c\left[\mathrm{kN} / \mathrm{m}^{2}\right]$ & 100 & 150 & --- & --- \\
\hline Friction angle $\phi$ [degrees] & 10 & 7 & & 0.15 \\
\hline Poisson's ratio & 0.3 & 0.3 & 0.25 & ----- \\
\hline Dilatancy angle $\psi$ [degrees] & 0 & 0 & --- & $7.5 \mathrm{E} 6[18]$ \\
\hline$E A$ & ---- & --- & $1 \mathrm{E} 5[18]$ \\
\hline$E I$
\end{tabular}

The load that this building places on the ground precisely calculated, regardless of the actual soil-structure relationship. The Tomb's load per unit area modelled on a rectangular surface. The next step is to allocate proper values to the soil properties after the geometry has been established in PLAXIS 2D. In the study, the Mohr-Coulomb constitutive model used for all soil layers and for this study Mohr-Coulomb synthetically denoted as MC model. The linear elastic, perfectly plastic Model (MC) makes the real soil behaviour easier to understand. The construction-stage calculations made 
simulate the behaviour of settlement in Plaxis. Note that $R_{\text {interf }}=1.0$ for a rigid interface (i.e. the interface has the same strength as the associated soil layer).

\subsection{Procedure of numerical modelling}

Step 1: Defining the soil stratigraphy.

Step 2: Create and assign the material data set.

Step 3: Define the structural elements.

Step 4: Initial geostatic stresses are generated in the mesh using gravity and a lateral earth pressure coefficient of 0.5 .

Step 5: Reset displacement to zero.

Step 6: Activation of load as UDL in stagged construction.

Step 7: Activating the secant pile in stagged construction.

Step 8: Activating the anchor and grout body and inserting its values.

Table 2 : Properties of anchor rod [16].

\begin{tabular}{|l|c|c|c|}
\hline \multicolumn{1}{|c|}{ Parameter } & Name & Value & Unit \\
\hline Material type & - & Elastic & - \\
\hline Axial stiffness & $E A$ & $500 \cdot 10^{3}$ & $\mathrm{kN}$ \\
\hline Out-of-plane spacing & $L_{s}$ & 2.5 & $\mathrm{~m}$ \\
\hline
\end{tabular}

Table 3: Properties of grout body [16].

\begin{tabular}{|l|c|c|c|}
\hline \multicolumn{1}{|c|}{ Parameter } & Name & Value & Unit \\
\hline Material type & - & Elastic & - \\
\hline Stiffness & $E$ & $7.07 \cdot 10^{6}$ & $\mathrm{kN} / \mathrm{m}^{2}$ \\
\hline Unit weight & $V$ & 0 & $\mathrm{kN} / \mathrm{m}^{3}$ \\
\hline Beam type & - & Predefined & - \\
\hline Predefined beam type & - & Massive circular beam & - \\
\hline Diameter & $D$ & 0.3 & $\mathrm{~m}$ \\
\hline Pile spacing & $L_{\text {spacing }}$ & 2.5 & $\mathrm{~m}$ \\
\hline \multirow{3}{*}{ Axial skin resistance } & Distribution & Linear & - \\
\cline { 2 - 5 } & $T_{\text {skin, } \text { end, max }}$ & 400 & $\mathrm{kN} / \mathrm{m}$ \\
\cline { 2 - 5 } & $T_{\text {skin, } \text { end, max }}$ & 400 & $\mathrm{kN} / \mathrm{m}$ \\
\hline Lateral resistance & Lateral resistance & Unlimited & - \\
\hline Base resistance & $F_{\text {max }}$ & 0 & $\mathrm{kN}$ \\
\hline Interface stiffness factor & Default values & Yes & - \\
\hline
\end{tabular}

\section{Results and discussion}

The modelling in Plaxis stated with staged construction with calculation type as Plastic. The secant pile in Plaxis 2D modelled as plate element. In the simulation, the initial stresses are generated through $K_{0}$ procedure, wherein the ratio of horizontal to vertical stress $K_{0}$ depends on the Poisson's ratio, as per the following equation

$K_{0}=\frac{\mu}{1-\mu}$.

The different geometrical parameters adopted for the present study are soil typologies, slope angle, footing width and spacing between footings. From the knowledge of soil mechanics, it is understood that each of the chosen parameters affect the generation of stress and strains in the foundation medium, and in turn influences the bearing capacity of the system. Varying soil typology introduces varying soil shear strength and stiffness parameters which result in varying stresses and strains in the soil medium, even under identical geometrical conditions. As the slope angle changes, the volume of soil participating in the passive resistance (generated from the direction of slope face) changes with the footing load, and hence, alters the stress and displacement conditions within the 
foundation. Change in the width of the footing induces different area of mobilization of the failure zones beneath a loaded footing, and hence alters the stress distribution beneath the footing.

The geometry and mesh of model is given in Fig. 4 and 5. Initially the load applied from 25 $\mathrm{kN} / \mathrm{m}^{2}$ and up to $100 \mathrm{kN} / \mathrm{m}^{2}$. Due to load of $25 \mathrm{kN} / \mathrm{m}^{2}$ the horizontal displacement recorded as 0.1395 $\mathrm{m}$, and vertical as $0.0902 \mathrm{~m}$. The degree of freedom of the nodes is connected to the displacement components in the current work. Each line element is subdivided into three nodes, each of which has a displacement value assigned to it. These three nodes contribute to the six-noded triangles, while a five-noded line portion results in a 15-noded triangle. In cases involving nails, anchors, or geogrids, it is discovered that 15-noded triangles produce more reliable results than six-noded triangles [19]. The effect of building load on the settlement modelled without and with the installation of pile also with Plaxis 2D. The effect on the length of pile was also studied. The modulus of elasticity $E_{s}$ for soil was calculated with the correlation of SPT and unconfined compression test of soil, the modulus of elasticity of top soil as 13000 and middle layer as 17000 [20, 21]. The simulation modelled according to the actual conditions of soil at the site.

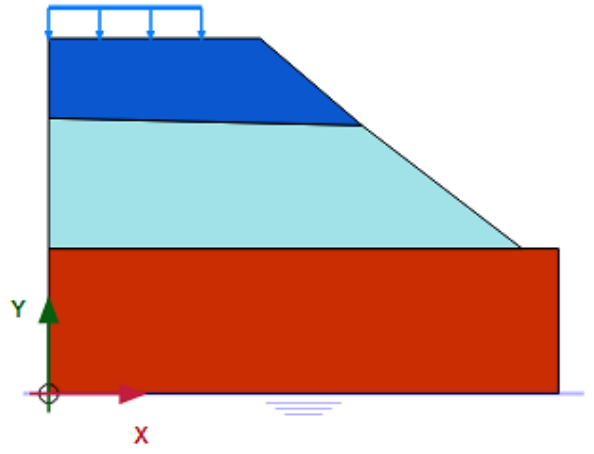

a)

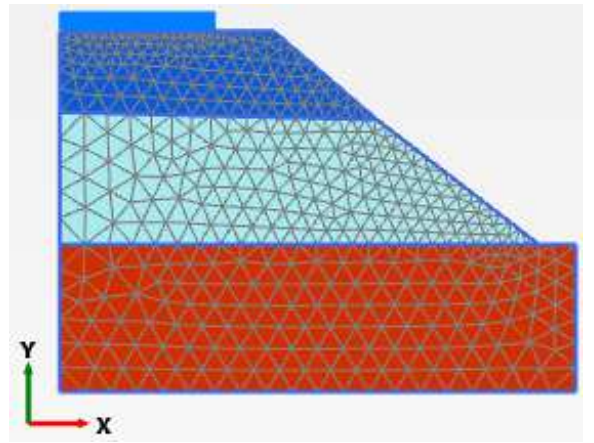

b)

Fig. 4: a) geometry of model, b) mesh generation.

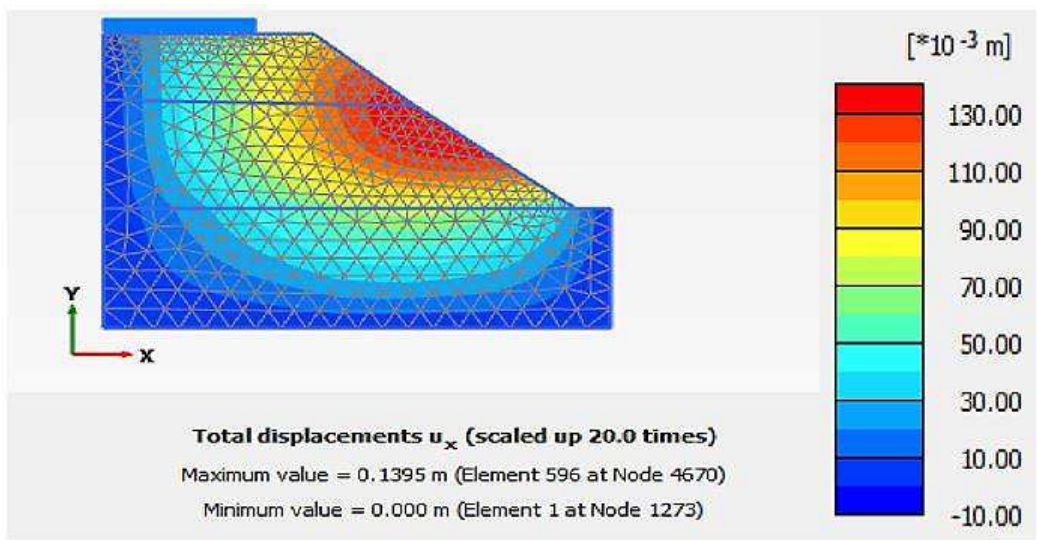

Fig. 5: a) Horizontal displacement.

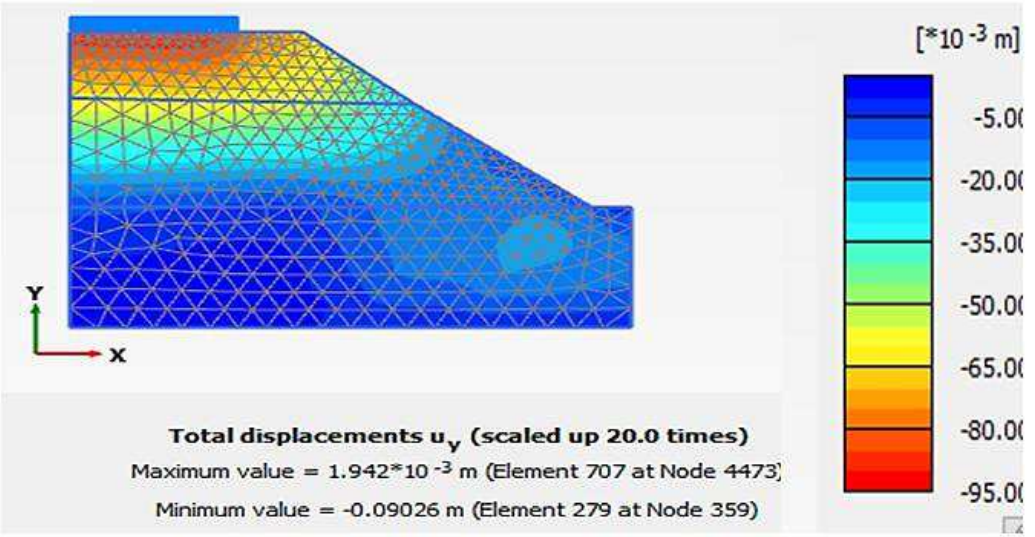

Fig. 5: b) Vertical displacement. 


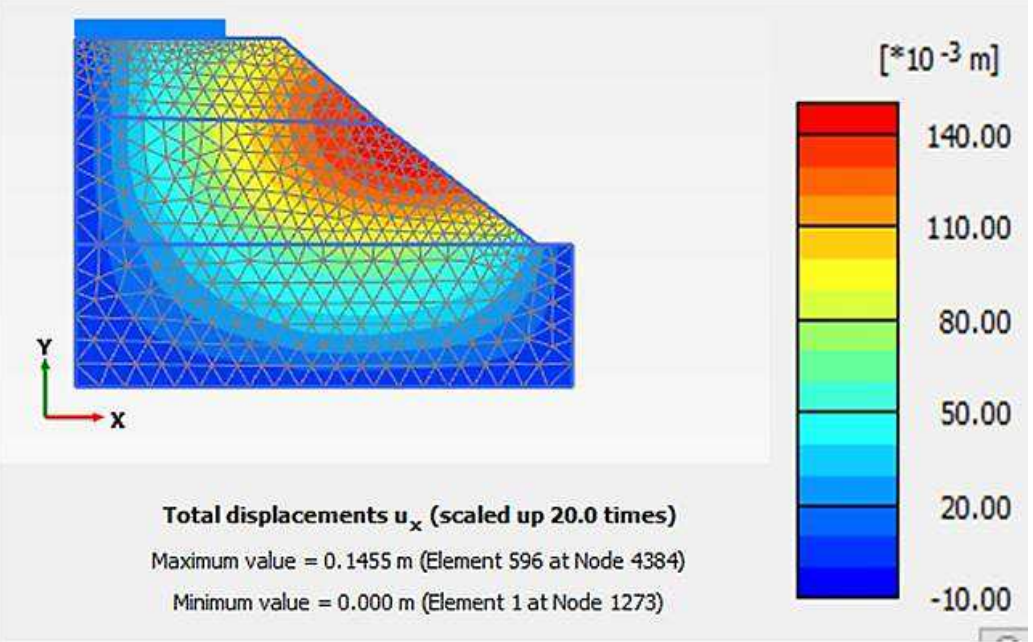

Fig. 6: a): Horizontal displacement.

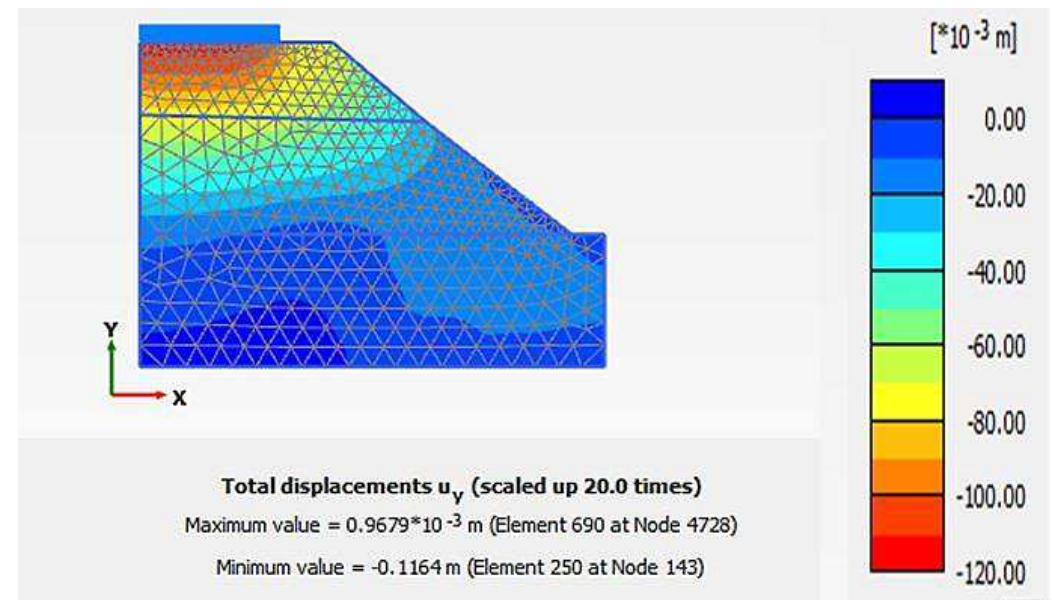

Fig. 6: b) Vertical displacement.

The load of $50 \mathrm{kN} / \mathrm{m}^{2}$ causes $0.1455 \mathrm{~m}$ of horizontal displacement as shown in Fig. $5 \mathrm{a}$, while vertical displacement as $0.1164 \mathrm{~m}$, similarly under the load of $100 \mathrm{kN} / \mathrm{m}^{2} 0.1656 \mathrm{~m}$ as horizontal, and $0.1892 \mathrm{~m}$ as vertical displacement shown in Fig. 6a, and 6b. The interface considered as rigid between secant pile and the surrounding soil, and there was no effect observed on vertical and horizontal displacement for it.

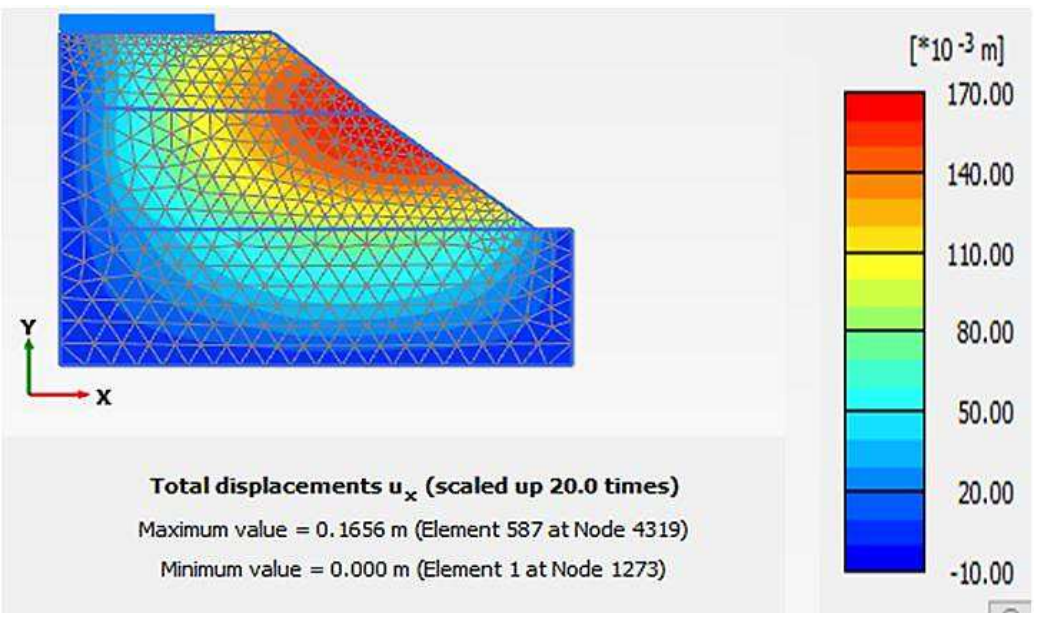

Fig. 7: a) Horizontal displacement. 


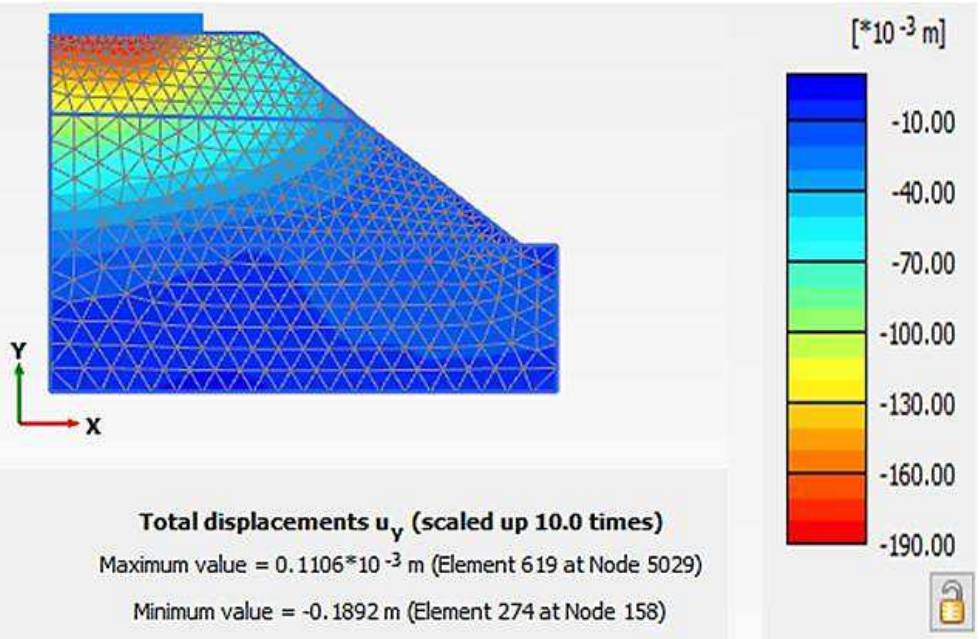

Fig. 7: b) Vertical displacement.

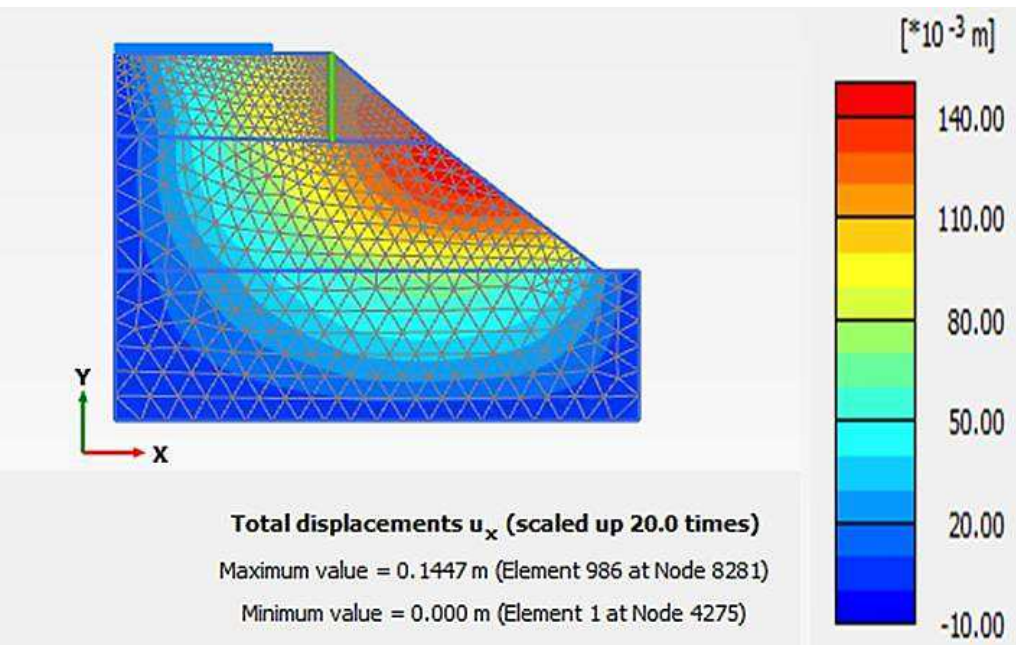

Fig. 8: a) Horizontal displacement.

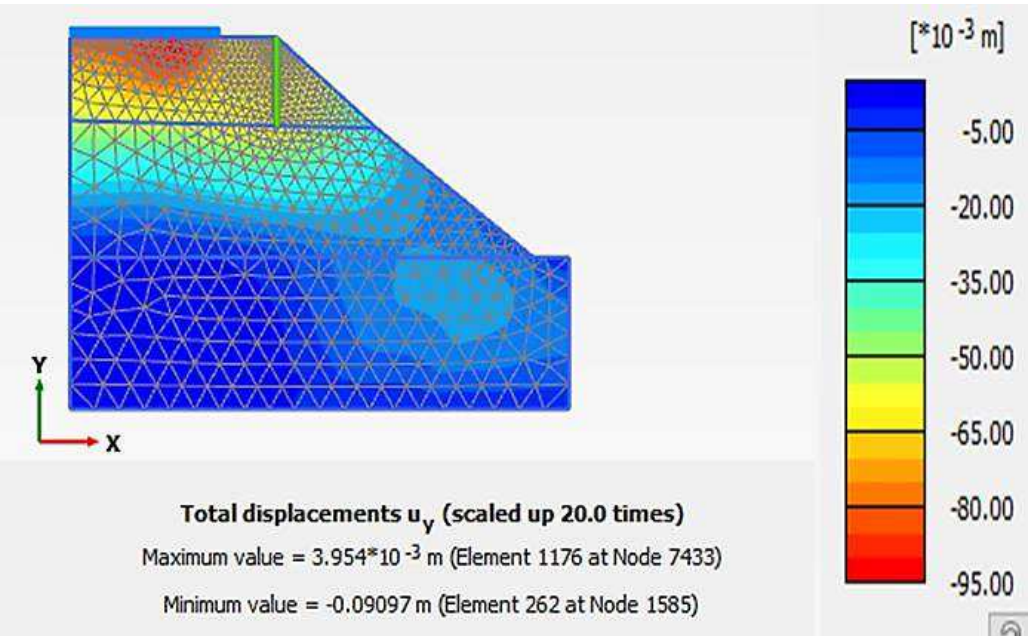

Fig. 8: b) Vertical displacement.

The effect of secant pile on the horizontal and vertical displacement is shown in Fig. 7, and it was worth noted that the effect of vertical displacement was comparatively smaller without the secant pile. The same load of $100 \mathrm{kN} / \mathrm{m}^{2}$ was applied in this case. The displacement reduced from $0.1892 \mathrm{~m}$ to $0.0907 \mathrm{~m}$ due to secant pile, while horizontal displacement from 0.1656 to $0.1447 \mathrm{~m}$. 


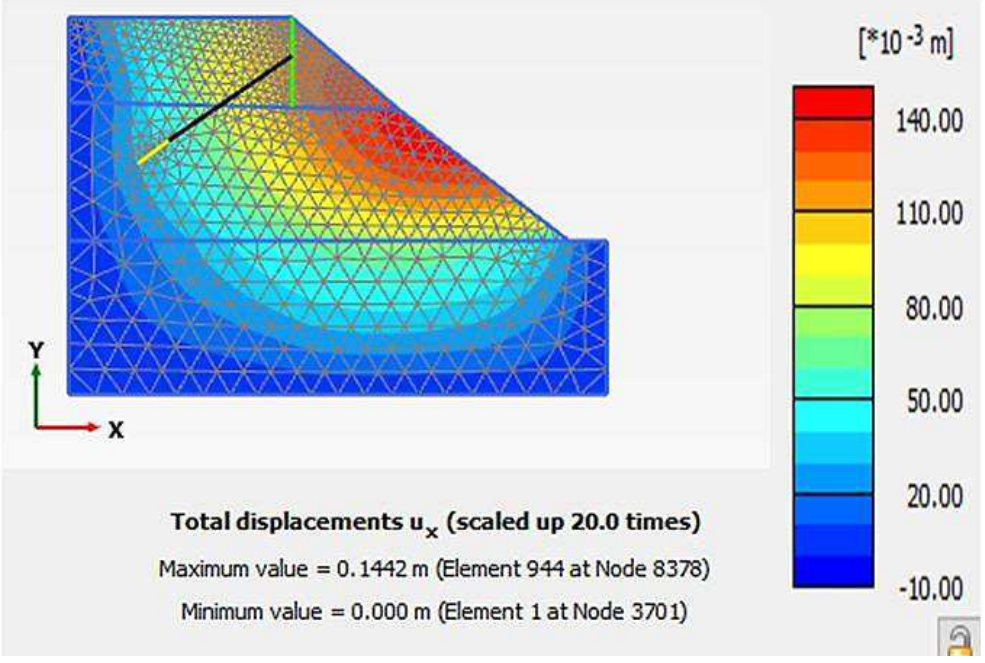

Fig. 9: a) Horizontal displacement.

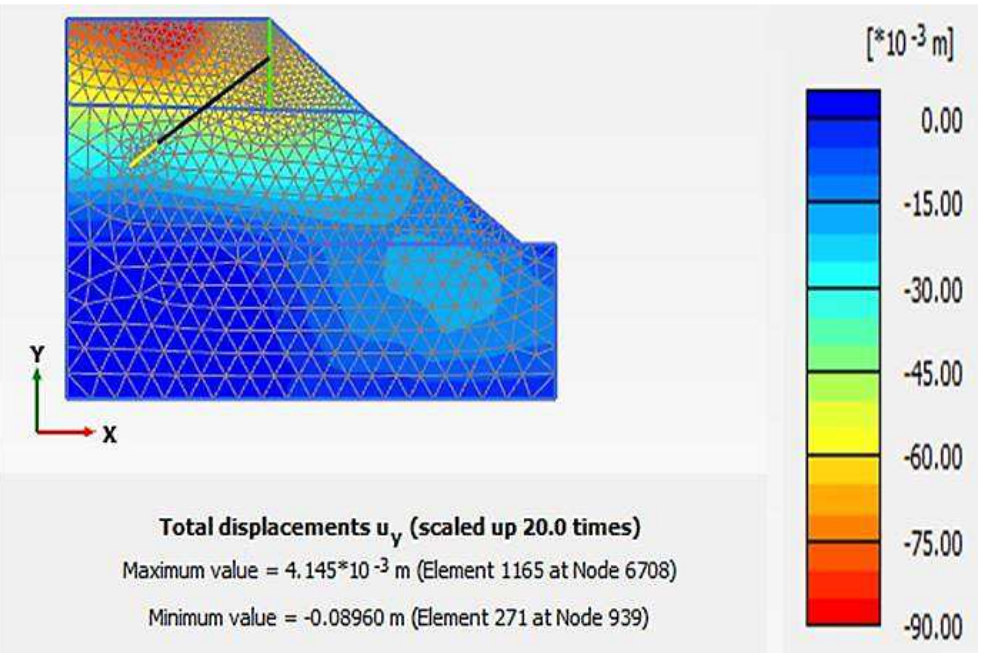

Fig. 9: b) Vertical displacement.

As from the Fig. 9, it was observed that there is little effect of anchorage of secant pile. The variation of vertical displacement with depth under different loading conditions is shown in Fig. 10. The bending moment variation of pile structure under the load is given, and maximum bending moment without anchor found as about $60 \mathrm{kNm}$ and with anchor as $46 \mathrm{kNm}$. The anchor was installed at the depth of $7 \mathrm{~m}$ from top of pile.

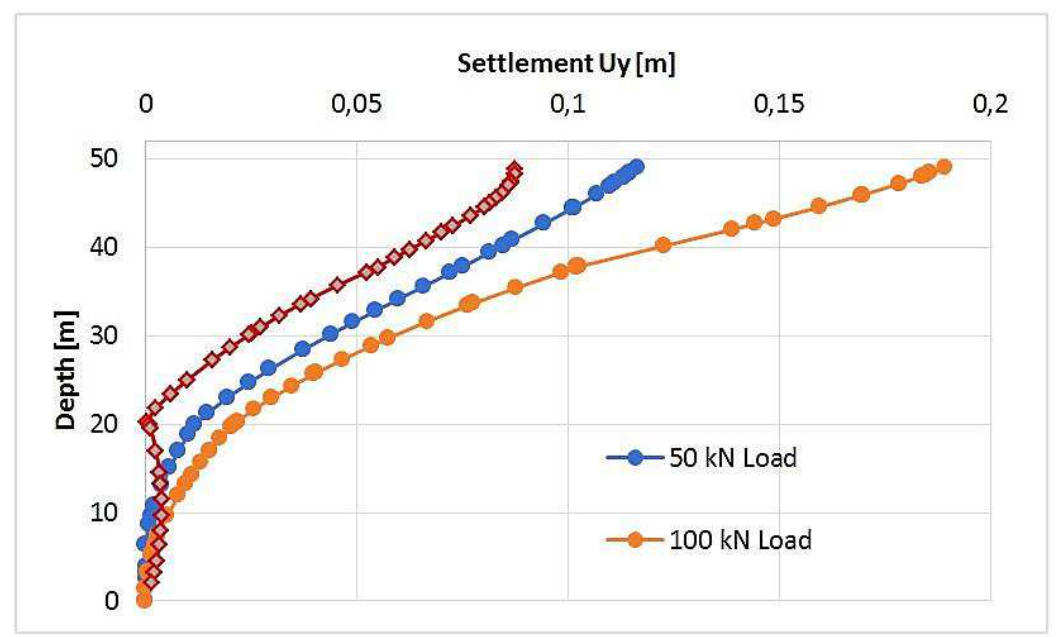

Fig. 10: Vertical displacement under different conditions. 


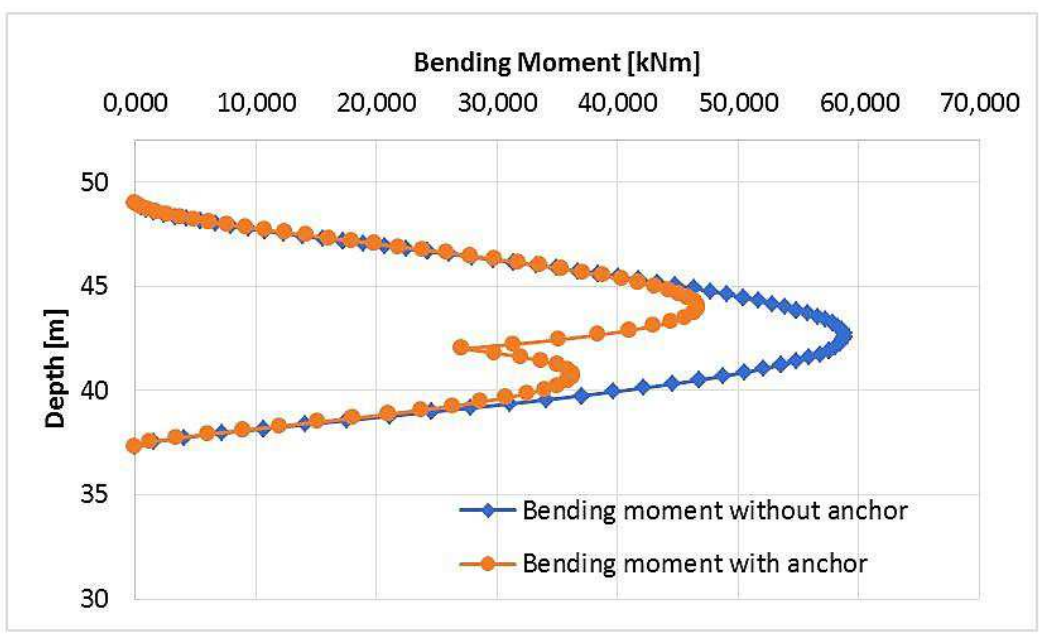

Fig. 11: Bending moment variation of pile.

The displacement horizontal and vertical was not affected because of location of pile on the crest of slope. A similar effect because of the length of secant pile observed. The slope is exposed to weathering conditions, the degradation of slope has an adverse impact on the Factor of safety of slope, it reduces from 1.36 to 1.10 with a change of slope from 45 to 35 as in Fig. 12. The installation of nails from face side of slope the settlement of Tomb reduced and Factor of Safety (FOS) increased.
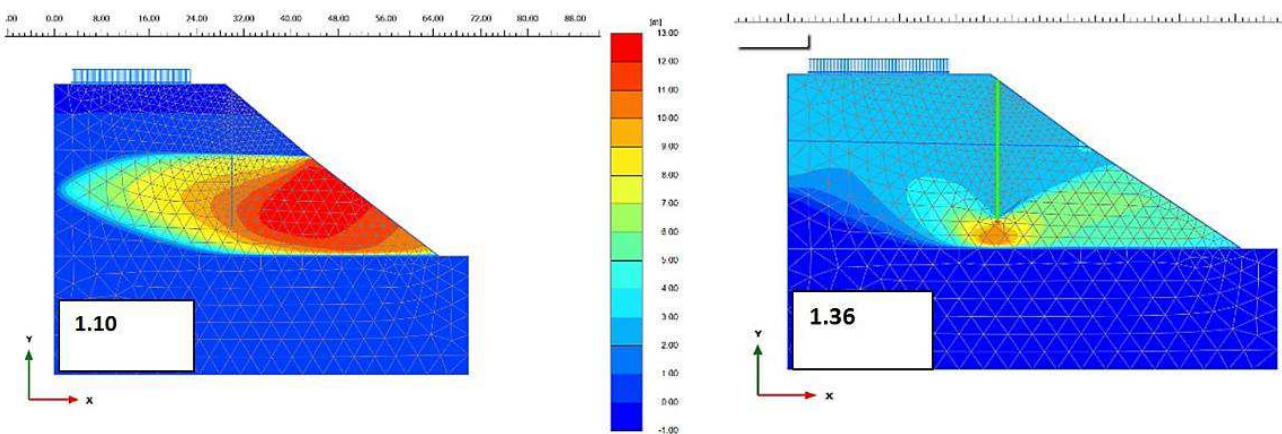

Fig. 12: Factor of safety.

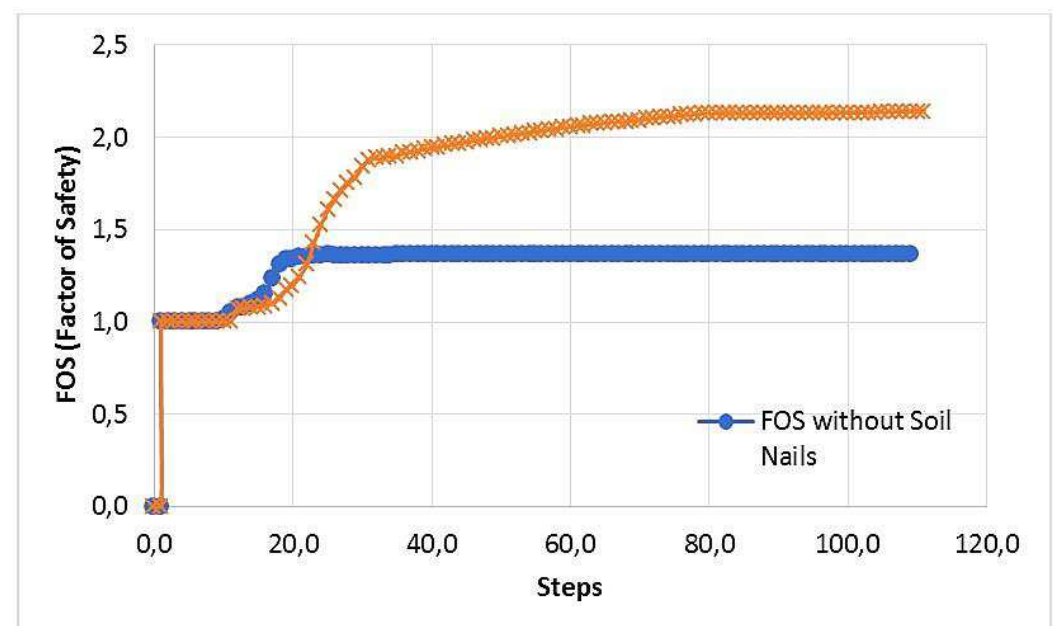

Fig. 13: Factor of safety with steps. 


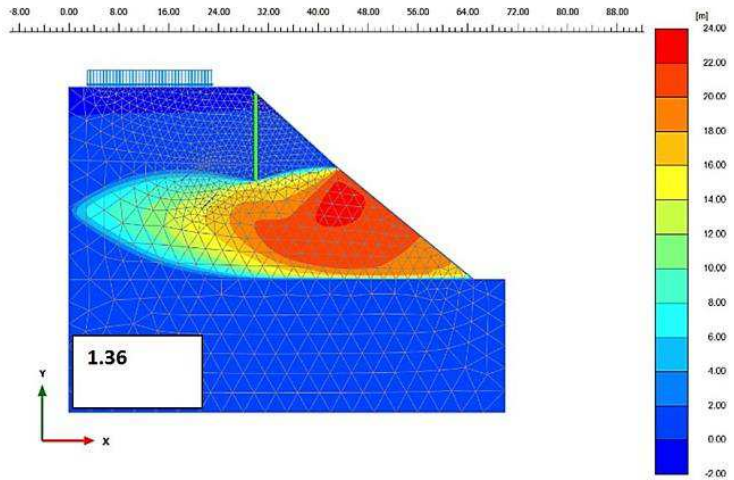

a)

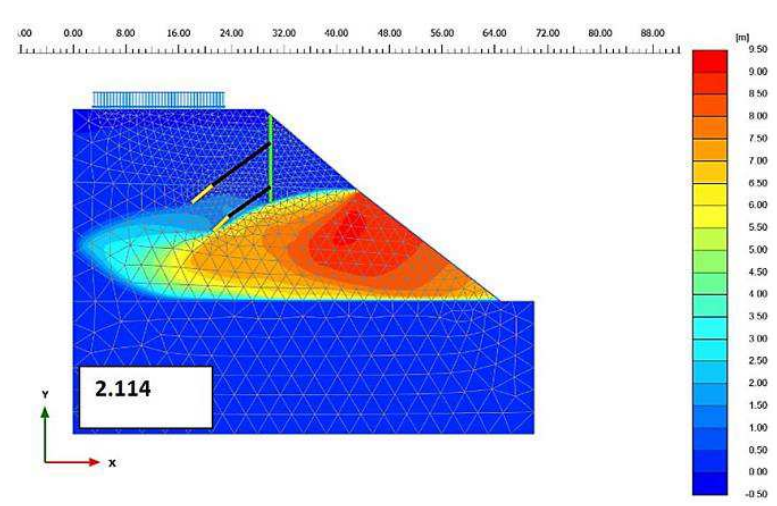

b)

Fig. 14: Factor of safety with steps: a) without nails, b) with nails.

\section{Conclusion}

The Plaxis 2D was used to simulate the laterally loaded pile on the slope due to building on the crest of slope. The soil behavior was defined using a Mohr-Coulomb model that was elastic-perfectly plastic. The pile was modelled with the plate element and linear elastic model. From the investigation of soil and building it was suggested that structure engineering aspects should be given the consideration. This research was to investigate the influence of structural elements on the settlement of the Tomb structure numerically.

- From the numerical modelling it was found that with increase of load the vertical settlement was increased, and reduced with the installation of secant pile.

- The installation of secant pile reduces Tomb's settlement, and with proper drainage and simple stabilizing technique of slope, the life of structure can be increased. The length of the secant pile should be not large, as $10 \mathrm{~m}$ is enough and economical.

- The factor of safety (FOS) of slope reduces with the increase of slope and increase with the installation of secant piles and structural nails.

- The restriction is related to the lateral contact between the pile and the soil, as in this study the rigid interface $R_{\text {inter }}=1$.

\section{References}

[1] HEMEDA, S.: 3D finite element coupled analysis model for geotechnical and complex structural problems of historic masonry structures: conservation of Abu Serga church, Cairo, Egypt. Heritage Science, 7(1), 2019, p. 6.

[2] NASSER, H. - AL HEIB, M. - DECK, O.: Influence of differential settlements on masonry structures. Conference: Computational Modelling of Concrete and Concrete Structures (EURO-C 2014), 2014, CRC PRESS.

[3] MANUAL, P. T.: Material Models Manual, Reference Manual and Scientific Manual. Version.

[4] JAMES, J. - SARASWATHY, R.: Performance of Fly Ash - Lime Stabilized Lateritic Soil Blocks Subjected to Alternate Cycles of Wetting and Drying. Civil and Environmental Engineering, 16(1), 2020, pp. 30-38.

[5] EPPICH, R. - MAHESSAR, K. - NAWAZ, S.: Monitoring movement At Makli. International Archives of the Photogrammetry, Remote Sensing \& Spatial Information Sciences, 2019.

[6] QASIM, Q. A.: Makli Hills Monument Thatta: History, Architecture, Conservation. Journal of Research in Architecture and Planning, 2014, p. 55.

[7] MEYERHOF, G.: The ultimate bearing capacity of foundations on slopes. Proc., 4th Int. Conf. on Soil Mechanics and Foundation Engineering, 1957.

[8] GRAHAM, J. - ANDREWS, M. - SHIELDS, D.: Stress characteristics for shallow footings in cohesionless slopes. Canadian Geotechnical Journal, 25(2), 1988. pp. 238-249.

[9] SHIELDS, D. - CHANDLER, N. - GARNIER, J.: Bearing capacity of foundations in slopes. Journal of geotechnical engineering, 116(3), 1990, pp. 528-537.

[10] SARAN, S. - SUD, V. - HANDA, S.: Bearing capacity of footings adjacent to slopes. Journal of geotechnical engineering, 115(4), 1989, pp. 553-573.

[11] ZHANG, J. et al., Model Test and Numerical Simulation of Single Pile Response under Combined Loading in Slope. Applied Sciences, 10(17), 2020, p. 6140. 
[12] JERGA, J. - KRAJČI, L'.: Damage in Concrete and its Detection by Use of Stress-Volumetric Strain Diagram. Civil and Environmental Engineering, 10(1), 2014, pp. 16-25.

[13] SAWANT, V. - SHUKLA, S. K.: Effect of edge distance from the slope crest on the response of a laterally loaded pile in sloping ground. Geotechnical and Geological Engineering, 32(1), 2014, pp. 197-204.

[14] IVÁNKOVÁ, O. - DROBNÝ, D. - MEDVECKÁ, S.: Effects of Bracing of High-Rise Buildings upon their Static and Dynamic Behavior. Civil and Environmental Engineering, 10(1), 2014, pp. 10-15.

[15] RAJESH, B.G. - CHUKKA, S. - DEY, A.: Finite Element Modeling of Embankment Resting on Soft Ground Stabilized with Prefabricated Vertical Drains. Elastic, 2018. 10, p. 06.

[16] BRINKGREVE, R., et al.: PLAXIS 2016. PLAXIS bv. The Netherlands, 2016.

[17] BRINKGREVE, R., et al.: Plaxis, finite element code for soil and rock analyses, 2D-Version 8, user's guide. 2002, Balkema.

[18] DIAS, D. - GRIPPON, J.: Numerical modelling of a pile supported embankment using variable inertia piles. Structural Engineering and Mechanics, 61(2), 2017, pp. 245-253.

[19] RAWAT, S. - GUPTA, A.: Analysis of a nailed soil slope using limit equilibrium and finite element methods. International Journal of Geosynthetics and Ground Engineering, 2(4), 2016, pp. 1-23.

[20] DAS, B. - SIVAKUGAN, N.: Settlements of shallow foundations on granular soil - an overview. International Journal of Geotechnical Engineering, 1(1), 2007, pp. 19-29.

[21] DAS, B. M.: Principles of foundation engineering. 2015, Cengage learning. 